\title{
KNOWLEDGE, AWAREENESS AND IMPACT OF CORONAVIRUS DISEASE LOCKDOWN ON TRAINING, FITNESS AND PERSONAL PARAMETERS: A SURVEY OF NIGERIIAN ATHLETES
}

\author{
Kayode Israel Oke, ${ }^{1, A, B, C}$ Olufemi Opeyemi Ogundiran,, D \\ Chidozie Emmanuel Mbada, ${ }^{3, B}$ Ekundayo Ogunkunle ${ }^{4, B}$ \\ ${ }^{1}$ Department of Physiotherapy, School of Basic Medical Sciences, College of Medical Sciences, University of Benin, Benin city, Edo state, \\ Nigeria \\ ${ }^{2}$ Department of Physiotherapy, Obafemi Awolowo University Teaching Hospitals Complex, Wesley Guild Hospital, llesa, Osun state, Nigeria \\ ${ }^{3}$ ORCID: 0000-0003-3666-7432. Department of Medical Rehabilitation, Obafemi Awolowo University, Ile-Ife, Osun state, Nigeria \\ ${ }^{4}$ Physiotherapy Division, National Sports Medicine Center, Abuja, Nigeria

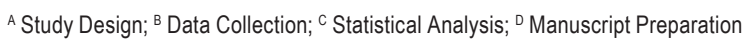 \\ Address for correspondence: \\ O.O. Ogundiran \\ Department of Physiotherapy, Obafemi Awolowo University Teaching Hospitals Complex, Wesley Guild Hospital, llesa, Osun state, Nigeria \\ E-mail: femi_diran@yahoo.com
}

\begin{abstract}
Ahstract The study was to assess the knowledge and awareness of COVID-19 pandemic, and the impact of lockdown restrictions on training, fitness and personal parameters of Nigerian athletes. This cross-sectional study recruited 578 elite athletes through an online survey using WhatsApp platform. An adapted questionnaire was used to obtain information on awareness, knowledge and impact of COVID-19 on athletes' characteristics. Descriptive and inferential statistics were used to analyze data. Alpha level was set at $p \leq 0.05$. There was high level of awareness (100\%) of COVID-19 pandemic among the respondents. The main source of awareness of COVID-19 was social media (68.4\%). Some of the respondents (55.9\%) had correct knowledge of COVID-19 causative organism. Age was significantly associated with knowledge about cause $\left(X^{2}=85.361 ; p=0.002\right)$ and spread $\left(X^{2}=27.715 ; p=0.023\right)$ of COVID-19 while gender was significantly associated with knowledge about the spread of the virus $\left(X^{2}=4.083 ; p=0.043\right)$. There were significant differences in physical fitness parameters $(p<0.05)$, eating pattern and body weight measures $(p<0.05)$, and general well-being $(p=0.001)$. Lockdown had negative impacts on hours of daily training, sleeping and eating patterns, physical fitness elements and the general well-being of the respondents.
\end{abstract}

Key WOrdls Nigerian athletes, coronavirus disease, knowledge, awareness, lockdown

\section{Introduction}

The Coronavirus Disease (COVID-19) pandemic is an unprecedented and ravaging global health crisis with consequent negative effects on societies and economies (Dawa, Narain, Bhatia, 2020; Sumner, Hoy, Ortiz-Juarez, 2020). Severe acute respiratory syndrome coronavirus 2 (SARSCov-2), which causes 
COVID-19, was declared a 'Public Health Emergency of International Concern' on 30 January 2020 by the World Health Organization (WHO) (WHO, 2020). The initial symptoms of the disease include fever, cough, dyspnea, myalgia, fatigue, sputum production, headache, hemoptysis and diarrhoea. There is associated bilateral lung ground-glass opacity on computed tomography imaging in almost all infected patients (Huang et al., 2020). Majority of patients with COVID-19 present relatively mild clinical features, however, the disease is associated with significant morbidity and mortality, particularly in older patients and those with chronic medical conditions such as hypertension, diabetes mellitus, asthma, or chronic obstructive pulmonary disease (Emami, Javanmardi, Pirbonyeh, Akbari, 2020).

As at May $31^{\text {st }}, 2020$, over three million confirmed cases of COVID-19 and more than 260,000 deaths have been recorded worldwide within five months, with the number of sick or dying people increasing by minutes across the globe (WHO, 2020). In Nigeria, according to the Nigeria Centre for Disease Control (NCDC), there are more than 18,000 confirmed cases and over 470 coronavirus-related deaths in the country (as at June 19 $9^{\text {th }}$ 2020). These figures have put Nigeria third in Africa, next only to South Africa and Egypt in terms of COVID-19 prevalence (WHO, 2020). In response, governments at all levels have adopted the use of varying degrees of "lockdown" restrictions to curb the spread of the virus and help people stay healthy at home (George, 2020). Other measures adopted by government authorities were social (physical) distancing, travel restrictions, closure of schools, worship centres, event centres which include stadia and gymnasia. Accordingly, sport activities have been put on hold owing to the COVID-19 pandemic in many parts of the world. The toll of the COVID-19 lockdown restrictions on sports is multifaceted.

Sports contributes to health, education and social inclusion objectives and empowerment (UN Reports, 2020). Sportsmen and women (athletes) undergo regular training and conditioning programmes which in turn enhance performance in their sports, boost confidence, prevent injuries, as well as help attain optimum physical fitness (Wilson, Loenneke, Jo, Wilson, Zourdos, Kim, 2012). Although, training and conditioning programmes can be performed individually, characteristically, for elite athletes, group is the ideal. Since the imposition of lockdown restrictions by national and state governments in order to curtail the spread of COVID-19, active group training or competition have been put on hold in many countries, including Nigeria. This interruption in the professional activity of athletes could have deleterious effects on their physical fitness, and psychosocial health, as well as have socioeconomic implications (Batey, Parry, 2020). In order to help inform policy on sports during and after the COVID-19 regime, there is a need to explore the impact of the coronavirus athletes' personal and sports characteristics. Therefore, this study assessed knowledge and awareness of COVID-19 pandemic, and the impact of lockdown restrictions on training, fitness and personal parameters of Nigerian athletes.

\section{Material and methods}

\section{Participants, instrument and procedures}

A nationwide online cross-sectional survey was carried out using WhatsApp platform. The choice of online survey was as a result of restrictions in movement and physical contacts that was imposed by the Nigerian government because of COVID-19. Study was conducted between $25^{\text {th }}$ of April and $1^{\text {st }}$ of May 2020. The online questionnaire was deactivated just as the total restrictions was about to be eased in many parts of Nigeria. Eligible respondents were active elite athletes across the country. The study recruited contact persons who were sport coaches in different sports. The contact persons helped in the recruitment of respondents for the study. An electronic 
questionnaire that sought information on socio-demographics, sports type, knowledge and awareness of COVID-19, sports participation/ training programme, training frequencies, training environment, eating and sleeping habits, general well-being and physical fitness elements before and during COVID-19 lockdown restrictions was used in this study. The tool was developed from the subjective well-being (SWB) questionnaire (adapted from WHO healthy policy paper) (Lindert, Bain, Kubzansky, Stein, 2015), and was tested for its content validity among experts in physiotherapy and sports science. Using google form, the questionnaire was hyperlinked to WhatsApp. The WhatsApp links containing the questionnaire was shared with the contact persons who in turn broadcasted it to their athlete contacts. Filled questionnaires were submitted via online links. Multiple responses from same individual/contact were programmed to be denied. The purpose of the study was clearly expressed and informed consent was sought from the respondents. Filling the survey indicates consent. Anonymity of the respondents was assured. In all, a total of 578 athletes duly completed the questionnaire.

\section{Statistical analysis}

Descriptive statistics of frequency and percentages were used to summarize data. Paired t-test was used to test for differences of the measured variables in order to assess the impacts of lockdown on the participants' characteristics before and during the lockdown. Chi-square analysis was used to test association between the participants' fitness parameters and demographic variables. Alpha level was set at $p \leq 0.05$. IBM Statistical Package for Social Sciences (SPSS) version 20.0 was used for the analysis.

\section{Resulls}

\section{Respondents' socio-demographics and sports characteristics}

Majority of the respondents were males (77.2\%), single (77.2\%) and in the $20-39$ years age group. $41.9 \%$ of the respondents were involved in combat sports athletes, $30.9 \%$ in soccer and $11.0 \%$ compete in athletic events (Table 1).

\section{Respondents' awareness and knowledge about COVID-19}

There was a high level of awareness (100\%) of COVID-19 pandemic among the respondents. The main source of awareness of COVID-19 was through the social media (68.4\%) (Table 2). Assessment on knowledge about COVID-19 shows that some of the respondents had correct knowledge of the causative organism for COVID-19 (55.9\%), its spread through contact with infected persons (33.8\%) and contaminated surfaces (14.0\%), 14 days incubation period before emergence of symptoms (96.3\%) and the spread of infection to others by an infected asymptomatic person (96.3\%). While having cure for COVID-19 is controvertible, $42.6 \%$ of the respondents indicated that COVID-19 cannot be cured, while $57.4 \%$ opined that it can be cured with chloroquine, traditional herbs, etc. Some of the respondents rightly assert that COVID-19 leads to higher fatality among the elderly (47.8\%) and that fever (70.6\%), cough (74.3\%) and pneumonia / breathing difficulty (83.1\%) are clinical signs of COVID-19 (Table 3). 


\section{Impact of the lockdown on respondents}

Paired t-test analysis results show there were significant differences in physical fitness parameters $(p<0.05)$, eating pattern and body weight measures $(p<0.05)$, and general well-being $(t=11.201 ; p=0.001)$. Only duration of training per day was significantly different $(p<0.05)$ of the training variables. There was a significant difference on respondents' daily training frequency, weekly training frequency, training environment, eating and sleeping patterns, general well-being and all physical fitness elements (cardiovascular endurance, muscular strength, joint flexibility, speed, agility and coordination level) (Table 4). The study also showed significant difference in the general wellbeing of the athletes as a result of COVID-19 lockdown measures $(t=11.201 ; p=0.001)$. Also, age was significantly associated with knowledge about cause $\left(X^{2}=85.361^{\dagger} ; p=0.002\right)$ and spread $\left(X^{2}=27.715 ; p=0.023\right)$ of COVID-19 while gender was significantly associated with knowledge about the spread of the virus $\left(X^{2}=4.083 ; p=0.043\right)$ (Table 5).

Table 1. Sociodemographic Profiles of the Respondents $(N=578)$

\begin{tabular}{|c|c|c|}
\hline & Frequency & Percentage \\
\hline \multicolumn{3}{|c|}{ Gender } \\
\hline Male & 446 & 77.2 \\
\hline Female & 132 & 22.8 \\
\hline \multicolumn{3}{|c|}{ Marital Status } \\
\hline Single & 446 & 77.2 \\
\hline Married & 128 & 22.1 \\
\hline Divorced & 4 & 0.7 \\
\hline \multicolumn{3}{|c|}{ Age } \\
\hline $20-24$ & 242 & 41.9 \\
\hline $25-29$ & 153 & 26.5 \\
\hline $30-34$ & 60 & 10.3 \\
\hline $35-39$ & 123 & 21.3 \\
\hline \multicolumn{3}{|c|}{ Type of Sport } \\
\hline Combat & 242 & 41.9 \\
\hline Soccer & 179 & 30.9 \\
\hline Athletics (Tracks and field events) & 64 & 11.0 \\
\hline Cricket & 13 & 2.2 \\
\hline Hockey & 13 & 2.2 \\
\hline Weight-lifting & 13 & 2.2 \\
\hline Swimming & 4 & 0.7 \\
\hline Tennis & 21 & 3.6 \\
\hline Volleyball and basketball & 17 & 2.9 \\
\hline Basketball & 12 & 2.1 \\
\hline \multicolumn{3}{|c|}{ Geopolitical zone } \\
\hline South west & 259 & 44.8 \\
\hline South east & 30 & 5.2 \\
\hline South south & 166 & 28.7 \\
\hline North central & 63 & 10.9 \\
\hline North east & 26 & 4.5 \\
\hline North west & 34 & 5.9 \\
\hline
\end{tabular}


Tahle 2. Awareness of COVID-19 among Respondents ( $N=578)$

\begin{tabular}{lcc}
\cline { 2 - 3 } & Frequency & Percentage \\
\hline \multicolumn{2}{c}{ Where did you first learn of COVID-19 } \\
\hline Friend/Relative/Social Media & 64 & 11.0 \\
Radio & 9 & 1.5 \\
Television & 51 & 8.8 \\
Social media & 395 & 68.4 \\
Other & 60 & 10.3 \\
\hline
\end{tabular}

Tahle 3. Knowledge of Respondents on Clinical Signs of COVID-19

\begin{tabular}{llcc}
\hline No. & \multicolumn{1}{c}{ Item } & Frequency & $\begin{array}{c}\text { Percentage of respondents } \\
\text { who gave correct answers }\end{array}$ \\
\hline 1. & What is the cause of COVID-19? & 323 & 55.9 \\
2. How is the causative agent spread? & 276 & 47.8 \\
3. What is the reservoir of agent of COVID-19? & 217 & 37.5 \\
4. How many days does it take for symptoms to manifest? & 557 & 96.3 \\
5. Can an infected person without symptoms infect others with whom they come in contact & 557 & 96.3 \\
6. COVID-19 can be treated or cured with chloroquine & 106 & 18.4 \\
7. COVID-19 can be treated or cured with traditional remedies, available vaccines, tea, & 149 & 25.7 \\
8. $\quad$ COVIID-19 does not have a cure & 246 & 42.6 \\
9. & Age group of people at high risk of COVID-19 infection (the elderly and those & 74.3 \\
\hline
\end{tabular}

Table 4. Paired t-test Analysis of the Impact of Lockdown on Respondents' Training and Physical Fitness Elements

\begin{tabular}{|c|c|c|c|c|}
\hline & \multirow{2}{*}{\multicolumn{2}{|c|}{ Mean \pm Std. Deviation }} & \multirow{3}{*}{ t-test } & \\
\hline & & & & \multirow{2}{*}{ P-value } \\
\hline & Before & During lockdown & & \\
\hline \multicolumn{5}{|c|}{ Training parameters } \\
\hline Frequency of training per day & $1.66 \pm 0.75$ & $1.53 \pm 0.97$ & 1.261 & 0.208 \\
\hline Frequency of training per week & $5.43 \pm 1.59$ & $5.09 \pm 1.89$ & 1.600 & 0.111 \\
\hline Hours of daily training & $2.80 \pm 1.23$ & $2.32 \pm 1.75$ & 2.643 & $0.009^{*}$ \\
\hline Training environment & $2.66 \pm 1.28$ & $2.18 \pm 1.42$ & 2.503 & $0.038^{*}$ \\
\hline \multicolumn{5}{|c|}{ Physical Fitness elements } \\
\hline Cardiovascular endurance & $3.09 \pm 0.93$ & $2.60 \pm 0.93$ & 4.367 & $0.001^{*}$ \\
\hline Muscular strength & $3.21 \pm 0.86$ & $2.57 \pm 0.87$ & 6.196 & $0.001^{*}$ \\
\hline Joint flexibility & $2.99 \pm 0.88$ & $2.49 \pm 0.82$ & 4.865 & $0.001^{*}$ \\
\hline Speed & $2.99 \pm 0.88$ & $2.40 \pm 0.84$ & 5.640 & $0.001^{*}$ \\
\hline Agility & $3.18 \pm 0.85$ & $2.46 \pm 0.88$ & 6.866 & $0.001^{*}$ \\
\hline Coordination & $3.14 \pm 0.85$ & $2.53 \pm 0.87$ & 5.873 & $0.001^{*}$ \\
\hline \multicolumn{5}{|c|}{ Personal characteristics } \\
\hline Body weight & $2.88 \pm 0.91$ & $2.39 \pm 0.88$ & 4.537 & $0.001^{*}$ \\
\hline Eating pattern & $2.76 \pm 0.58$ & $1.88 \pm 0.72$ & 2.052 & $0.041^{*}$ \\
\hline Sleeping pattern & $7.28 \pm 1.52$ & $8.08 \pm 2.75$ & -2.945 & $0.004^{*}$ \\
\hline
\end{tabular}

*Statistically Significant. 
Table 5. Chi square test of Association of Knowledge of COVID-19 and Sociodemographic Variables

\begin{tabular}{lcc} 
& $\mathrm{X} 2$ & $\mathrm{p}$-value \\
\hline Age vs Knowledge about the spread of COVID-19 & $85.361^{\text {t+ }}$ & $0.002^{*}$ \\
Age vs Knowledge about the cause of COVID-19 & $27.715^{\text {tt }}$ & $0.023^{*}$ \\
Gender vs Knowledge about the spread of COVID-19 infection & $4.083^{\text {t+ }}$ & $0.043^{*}$ \\
\hline
\end{tabular}

†† Chi-square; * Statistically Significant.

\section{Discussion}

The objective of this study was to assess knowledge and awareness of COVID-19 pandemic, and the impact of lockdown restrictions on training, fitness and personal parameters of Nigerian athletes. The findings from this study showed a high level of awareness of the COVID-19 pandemic among the respondents. This could be as a result of the wide publicity about the outbreak since its emergence in Wuhan, China. An Iranian study has indicated that high exposure to the information provided by various governments through numerous media platforms about the virus since its outbreak has resulted in high level of awareness about COVID-19 among populace (Erfani, Shahriarirad, Ranjbar, Mirahmadizadeh, Moghadami, 2020). The high level of awareness recorded in this study is similar to types recorded in other studies conducted in China, Egypt and Nigeria about awareness of the general populace about the dreaded coronavirus disease (Roy, Tripathy, Kar, Sharma, Verma, Kaushal, 2020; Abdelhafiz et al., 2020 ; Olapegba et al., 2020). Reports have also indicated that people's level of awareness about an infectious disease is pertinent to one's behavior about preventing it (Choi, Yang, 2010; Hussain, Hussain, Hussain, 2012). Social media was the greatest source of awareness in the present study as it served as source of information for $68.4 \%$ of the respondents. This observation is in tandem with the reports of studies from other countries like UAE (Bhagavathula, Aldhaleei, Rahmani, Mahabadi, Bandari , 2020), Egypt (Abdelhafiz et al., 2020), and China (Roy, Tripathy, Kar, Sharma, Verma, Kaushal, 2020).

With regards to the respondents' knowledge about the cause of COVID-19, less than $50 \%$ of the respondents attributed the cause of COVID-19 to different sources other than SARSCov-2. A similar finding has been reported in Egypt where respondents attributed other factors like $5 \mathrm{G}$ telecommunication technology as the causes of COVID-19 pandemic (Abdelhafiz et al., 2020). Also, more than half of the respondents indicated that COVID-19 can be cured with chloroquine, traditional herbs, etc. The belief that COVID-19 can be cured may be predicated on information made available on different media on possible curative effects of hydroxychloroquine and other traditional herbs (Gautret et al., 2020; Balachandar et al., 2020). This is contrary to the fact that COVID-19 currently has no cure (WHO, 2020). Furthermore, there was a wrong notion by some of the respondents that that people belonging to other age groups other than the elderly people were most vulnerable to COVID-19. This position contradicts officials reports by the WHO that elderly people are most vulnerable to this disease (WHO, 2020).

The finding from the present study showed that age was associated with knowledge about the cause and spread of COVID-19. This finding is in agreement with the reports of other studies on knowledge about COVID-19 causation and spread among people of different age groups of United Arab Emirates who are health care workers (Bhagavathula etal., 2020) and members of general public in Malaysia (Azlan, Hamzah, Sern, Ayub, Mohamad, 2020). Furthermore, this study revealed that gender was associated with knowledge of cause and spread of COVID-19. There exists in literature significant association between gender and proper hand hygiene (Azlan, Hamzah, Sern, 
Ayub, Mohammad, 2020; Bhagavathula et al., 2020), but the authors did not find any report of association of gender with knowledge as found in the present study.

The outcome of this study also showed that COVID-19 lockdown measure had a significant negative impact on athletes" training environment, eating and sleeping habits, general well-being and physical fitness elements. This observation may be partly due to the fact that the lockdown period has made access to outdoor training environment such as pitches and gymnasia becomes difficult. Therefore, these athletes resulted to training more at home at lesser frequencies daily and weekly, sleeping for more hours and consuming more food than before the lockdown experience. Studies have reported that adequacy of training facilities and equipment (Can, 2010) and presence of teammates, availability of coaches and social supports are indispensable contributing factors to successful and good athletic performance (Kubiak, 2012). Nevertheless, the study showed that there is a significant difference in the number of hours training per day the athletes experienced before and during the lockdown. This imply that though the athletes possibly managed to train at home, they could not accumulate the desired or required training duration. However, there was no significant difference in daily and weekly training frequencies of the athletes before and during the lockdown or movement restrictions. The implications of this finding are that Nigerian athletes may have been finding means to engage in training in their respective homes on daily basis despite lack of access to the right environment or pitches for their training. Furthermore, the outcome of the study revealed that physical fitness parameters of the athletes were significantly reduced following COVID-19 lockdown restriction. It is adducible that COVID-19 restrictions have significant deleterious effect on physical fitness elements of elite athletes, even if it is short term. This may in turn negatively affect sports performance of Nigerian athletes in post COVID-19 era. Literature has suggested that isolation from sport has disadvantages of decreasing physical and mental health and quality of life even among elite athletes (Dehkodia, 2011). To the best of the authors' knowledge, this is the first study to report the knowledge and awareness of COVID-19 pandemic and its impacts on athletes characteristics in Nigeria.

\section{Limitation}

Measurement of physical fitness parameters were based on self-report. Therefore, it is difficult to eliminate over or under-reporting of the variables.

\section{Conclusion}

There was high level of awareness and moderate level of knowledge about causes and spread of COVID-19 among Nigerian athletes. COVID-19 lockdown restrictions led to significant reduction in athletes' physical fitness parameters, general well-being and hours of training per day but increase in body weight and eating pattern.

\section{Funding}

The authors received no financial support for the research and/or authorship of this article. 


\section{References}

Abdelhafiz, A.S., Mohammed, Z., Ibrahim, M.E., Ziady, H.H., Alorabi, M., Ayyad, M., Sultan, E.A. (2020). Knowledge, Perceptions, and Attitude of Egyptians Towards the Novel Coronavirus Disease (COVID-19). J Community Health. DOI: 10.1007/ s10900-020-00827-7.

Azlan, A.A., Hamzah, M.R., Sern, T.J., Ayub, S.H., Mohamad, E. (2020). Public knowledge, attitudes and practices towards COVID-19: A cross-sectional study in Malaysia. PLOS ONE, 15 (5), e0233668. DOI: 10.1371/journal.pone.0233668.

Balachandar, V., Kaavya, J., Mahalaxmilyer, A., Vellingiri, B., Jayaramayya, K., lyer, M., Narayanasamy, A., Govindasamy, V., Giridharan, B., Ganesan, S., Venugopal, A., Venkatesan, D., Ganesan, H., Rajagopalan, K., Rahman, P.K.S.M., Cho, S.G, Kumar, N.S., Subramaniam, M.D. (2020). COVID-19: A promising cure for the global panic. Science of the Total Environment, 725 (1). DOI: 10.1016/j.scitotenv.2020.138277.

Batey, J., Parry, K. (2020). Coronavirus: why self-isolation brings mental health strain for elite athletes. Retrieved from: https:// theconversation.com/coronavirus-why-self-isolation-brings-mental-health-strain-for-elite-athletes-135273 (31.05.2020).

Bhagavathula, A.S., Aldhaleei, W.A., Rahmani, J., Mahabadi, M.A., Bandari, D.K. (2020). Knowledge and Perceptions of COVID-19 Among Health Care Workers: Cross-Sectional Study. JMIR Public Health Surveill; 6 (2), e19160.

Can, S. (2010). Determination of the factors motivating and motivation level of the weightlifters participating in Turkish weightlifting championship. Procedia Social and Behavioral Sciences, 2, 4245-4249.

Choi, J.S., Yang, N.Y. (2010). Perceived knowledge, attitude, and compliance with preventive behavior on influenza A (H1N1) by university students. J. Korean Acad. Adult Nurs., 22 (3), 250-259.

Dawa, N., Narain, J.P., Bhatia, R. (2020). COVID-19 Pandemic and the Crucial Role of Health System Preparedness. J. Vaccines Vaccin. S4:003. DOI: 10.3528/2157-7560.20.S4.003.

Dehkordia, A.G. (2011). The comparison between athlete females and non-athlete females regarding to general health, mental health, and quality of life. Procedia Social and Behavioral Sciences, 15, 1737-1741.

Emami, A., Javanmardi, F., Pirbonyeh, N., Akbari, A. (2020). Prevalence of Underlying Diseases in Hospitalized Patients with COVID-19: a Systematic Review and Meta-Analysis. Arch Acad Emerg. Med. 8 (1), e35.

Erfani, A., Shahriarirad, R., Ranjbar, K., Mirahmadizadeh, A., Moghadami, M. (2020). Knowledge, Attitude and Practice toward the Novel Coronavirus (COVID-19) Outbreak: A Population-Based Survey in Iran. [Preprint]. Bull World Health Organ, E-pub: 30 March. DOI: 10.2471/BLT.20.256651.

Gautret, P., Lagier, J.C., Parola, P., Hoang, V.T., Meddeb, L., Mailhe, M., Doudier, B., Courjon, J., Giordanengo, V., Vieira, V.E., Dupont, H.T., Honoré, S., Colson, P., Chabrière, E., La Scola, B., Rolain, J. M., Brouqui, P., Raoult, D. (2020). Hydroxychloroquine and azithromycin as a treatment of COVID-19: results of an open-label non-randomized clinical trial. International Journal of Antimicrobial Agents, 105949. Advance online publication. DOI: 10.1016/j.jjantimicag.2020.105949.

George, L. (2020). Nigeria to extend coronavirus lockdowns for 14 more days: President Buhari. Retrieved from: https://www.reuters. com/article/us-health-coronavirus-nigeria/nigeria-to-extend-coronavirus-lockdowns-for-14-more-days-president-buhariidUSKCN21V1US (30.05.2020).

Huang, C., Wang, Y., Li, X., Ren, L., Zhao, J., Hu, Y., Zhang, L., Fan, G., Xu, J., Gu, X., Cheng, Z., Yu, T., Xia, J., Wei, Y., Wu, W., Xie, X., Yin, W., Li, H., Liu, M., Xiao, Y., Gao, H., Guo, L., Xie, J., Wang, G., Jiang, R., Gao, Z., Jin, Q., Wang, J., Cao, B.(2020). Clinical features of patients infected with 2019 novel coronavirus in Wuhan, China. Lancet, 395 (10223), 497-506. DOI: 10.1016/ S0140-6736(20)30183-5.

Hussain, Z.A., Hussain, S.A. Hussain, F.A. (2012). Medical students' knowledge, perceptions, and behavioral intentions towards the H1N1 influenza, swine flu, in Pakistan: a brief report. Am. J. Infect. Control, 40 (3), e11-e13. DOI: 10.1016/j.ajic.2011.12.004.

Kubiak, C. (2012). Perceived factors influencing athletic performance across career stages. (C-essay in sport psychology 61-90 hp). School of Social and Health Sciences. Halmstad University.

Lindert, J., Bain, P.A., Kubzansky, L.D. Stein, C. (2015). Well-being measurement and the WHO health policy Health 2010: systematic review of measurement scales. European Journal of Public Health, 25 (4), 731-740.

Nigeria Centre for Disease Control (NCDC). COVID-19 case update. Retrieved from: https://twitter.com/NCDCgov (9.04.2020).

Olapegba, P.O., Ayandele, O., Kolawole, S.O., Oguntayo, R.O., Gandi, J.C., Dangiwa, A.L., Ottu, A., lorfa, S.K. (2020). A Preliminary Assessment of Novel Coronavirus (COVID-19) Knowledge and Perceptions in Nigeria.

Roy, D., Tripathy, S., Kar, S.K., Sharma, N., Verma, S.K., Kaushal, V. (2020). Study of knowledge, attitude, anxiety \& perceived mental healthcare need in Indian population during COVID-19 pandemic. Asian Journal of Psychiatry, Apr; 51, 102083. DOI: 10.1016/j. ajp.2020.102083. 
Sumner, A., Hoy, C., Ortiz-Juarez, E. (2020). Estimates of the impact of COVID-19 on global poverty (Wider Working Paper 2020/43). World Institute for Development Economic Research (UNU-WIDER). Retrieved from: https://www.wider.unu.edu/publication/ estimates-impact-covid-19-global-poverty. DOI:10.35188/UNU-WIDER/2020/800-9 (30.08.2020).

The impact of COVID-19 on sport, physical activity and well-being and its effects on social development. United Nations Department of Economic and Social Affairs Social Inclusion. Retrieved from: https://www.un.org/development/desa/dspd/2020/05/covid-19sport/15 May, 2020.

Wilson, J.M., Loenneke, J.P., Jo, E., Wilson, G.J., Zourdos, M.C., Kim, J. (2012). The Effects of Endurance, Strength, and Power Training on Muscle Fiber Type Shifting. Journal of Strength and Conditioning Research, 26 (6), 1724-1729.

World Health Organization (2020). Q\&A on coronaviruses (COVID-19). Retrieved from: https://www.who.int/news-room/q-a-detail/q-acoronaviruses (4.04.2020).

World Health Organization (2020). Coronavirus disease (COVID-2019) situation reports. Retrieved from: https://www.who.int/ emergencies/diseases/novel-coronavirus-2019/situation-reports (6.06.2020).

Cite this anticle aS: Oke, K.I., Ogundiran, O.O., Mbada, C.E., Ogunkunle, E. (2021). Knowledge, Awareness and Impact of Coronavirus Disease Lockdown on Training, Fitness and Personal Parameters: A Survey of Nigerian Athletes. Central European Journal of Sport Sciences and Medicine, 2 (34), 67-75. DOI: 10.18276/cej.2021.2-06. 